\title{
Higher order mode dielectric resonator antenna excited using microstrip line
}

\author{
Irfan Ali, Mohd Haizal Jamaluddin, Abinash Gaya \\ Wireless Communication Centre, School of Electrical Engineering, Universiti Teknologi Malaysia, Malaysia
}

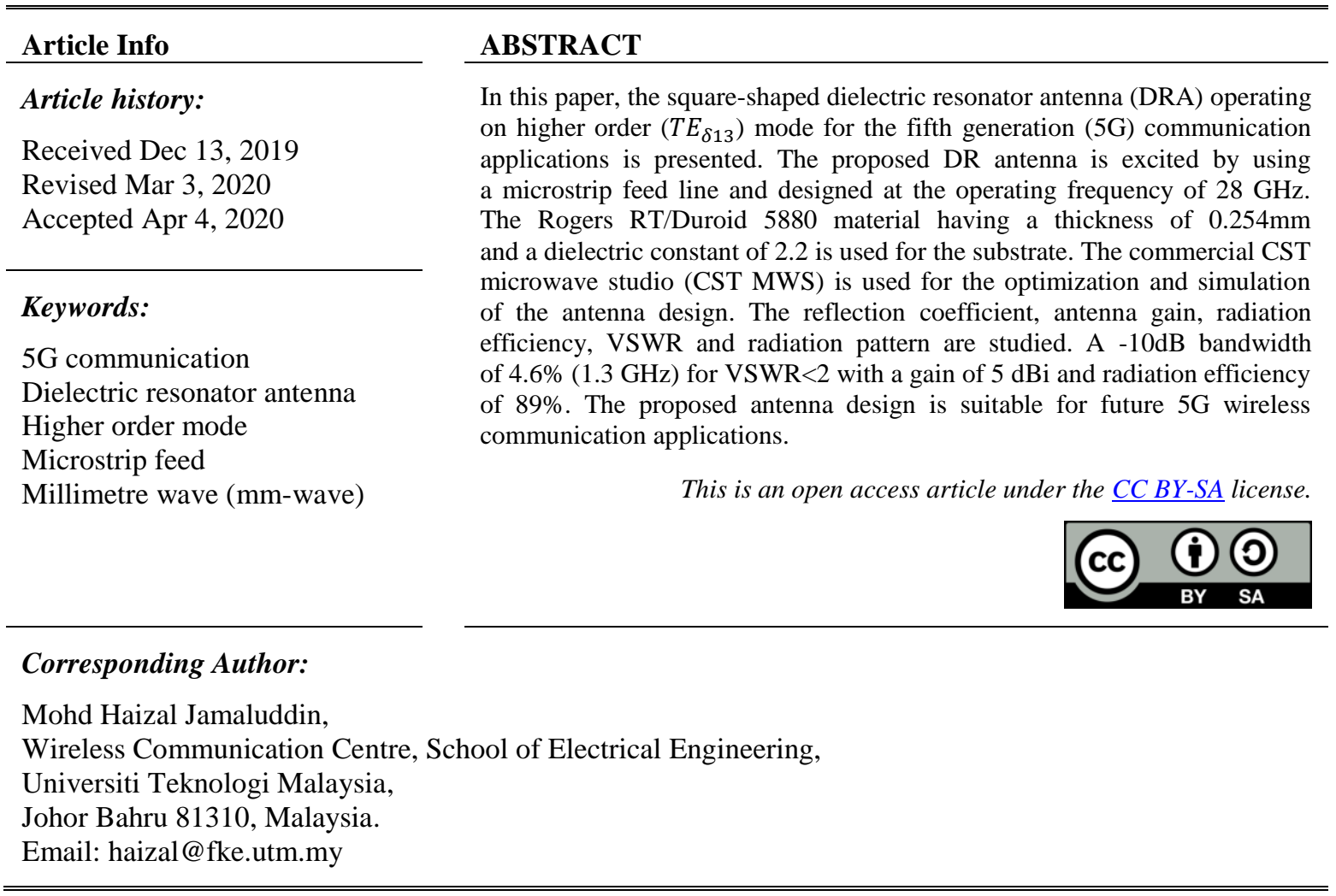

\section{INTRODUCTION}

Due to the fast revolution in the telecommunication industry, wireless technology has evolving from first generation $(1 \mathrm{G})$ to fifth generation $(5 \mathrm{G})$ [1]. In recent years, the increasing number of wireless devices and services have triggered the engineers, scientists, researchers in academia and industries to move on to the future generation $(5 \mathrm{G})$ communication technology, which is expected to be introduced by 2020 and beyond. It is an ultimate goal of all scientists and researchers to build a wireless world in which all devices are connected with one another wirelessly. In Today's modern wireless era, antennas with high radiation efficiency, compact size, high gain, and large bandwidth are required [2, 3]. Antennas are an essential part of any wireless communication systems. The two classes of antennas, named microstrip patch antennas (MSA) and dielectric resonator antennas (DRAs) are extensively used in the applications of modern communication. Recently, research antenna community is paying more attention to dielectric resonator antenna (DRA) due to its alluring features of higher radiation efficiency, relatively large impedance bandwidth, low profile, design flexibility, ease of excitation schemes and ease of fabrication [4-12]. In addition, DRA can be excited by different feeding methods like microstrip feed line [13], probe feeding $[14,15]$, aperture coupling [16, 17], and coplanar waveguide (CPW) [16]. DRA comes in various shapes such as cylindrical [18, 19], rectangular [20, 21], Hemi-spherical [22] and triangular [23, 24]. Thus, DRA is considered as alternative to low gain metallic conventional antennas and is best candidate for the $5 \mathrm{G}$ applications [25].

Several methods have been proposed in the literature to improve the bandwidth and gain of DRA antenna, including stacking DRAs [26, 27] and EBG structure [28, 29]. In this paper, dielectric resonator 
antenna (DRA) based on higher order $T E_{\delta 13}$ mode using microstrip feed line for gain and bandwidth improvement with high radiation efficiency at millimeter wave frequency (mm-wave) of $28 \mathrm{GHz}$ is presented. A lot of work has been done previously on the fundamental mode at a lower frequency, but a limited work has been done on the higher order mode especially at millimeter wave frequencies. The excitation of higher order mode is simple in structure and does not increase complexity as compared to other techniques mentioned. This paper is organized as follows: The antenna geometry configuration and design process are described in section 2. The results and discussion part of the proposed structure are described in section 3 . The conclusion of the paper is given in section 4 .

\section{ANTENNA GEOMETRY}

The resonant frequency $f_{o}$ of dielectric resonator antenna (DRA) is computed as follows [30]:

$$
f_{o}=\frac{c}{2 \pi \sqrt{\varepsilon_{r}}} \sqrt{k_{x}^{2}+k_{y}^{2}+k_{z}^{2}}
$$

Where $\varepsilon_{r}$ is the relative permittivity of the DRA, c is the speed of light (in free space), $k_{x}, k_{y}$ and $k_{z}$. Symbols denote the wave number in the $\mathrm{x}, \mathrm{y}$ and $\mathrm{z}$ directions, respectively. The proposed antenna geometry is shown in Figure 1. The antenna is resonating at the operating frequency of $28 \mathrm{GHz}$. The squared DRA has length, width and height $(a \times b \times d)$ with a dielectric constant of $\varepsilon_{r s}$. The DRA is placed on the Rogers RT/Duroid 5880 substrate with a thickness of $h_{s}$ and relative permittivity of $\varepsilon_{r d}$. The DRA is excited by using $50 \Omega$ microstrip feed line. Table 1 lists the optimized dimensions of the proposed antenna design.

Table 1. Optimized dimensions of the proposed DR antenna, all dimensions are in millimetres (mm)

\begin{tabular}{ccc}
\hline Parameters & Description & Dimension \\
\hline$L_{g}$ & Ground length & 20 \\
$W_{g}$ & Ground width & 20 \\
$h_{g}$ & Ground height & 0.0175 \\
$L_{s}$ & Substrate length & 20 \\
$W_{s}$ & Substrate width & 20 \\
$h_{s}$ & Substrate height & 0.254 \\
Substrate $\varepsilon_{r}$ & Dielectric constant & 2.2 \\
$a$ & DRA length & 3.5 \\
$b$ & DRA width & 3.5 \\
$d$ & DRA height & 5.1 \\
DRA $\varepsilon_{r}$ & Dielectric constant & 10 \\
$L_{f}$ & Feed length & 9.78 \\
$W_{f}$ & Feed width & 1.65 \\
\hline
\end{tabular}

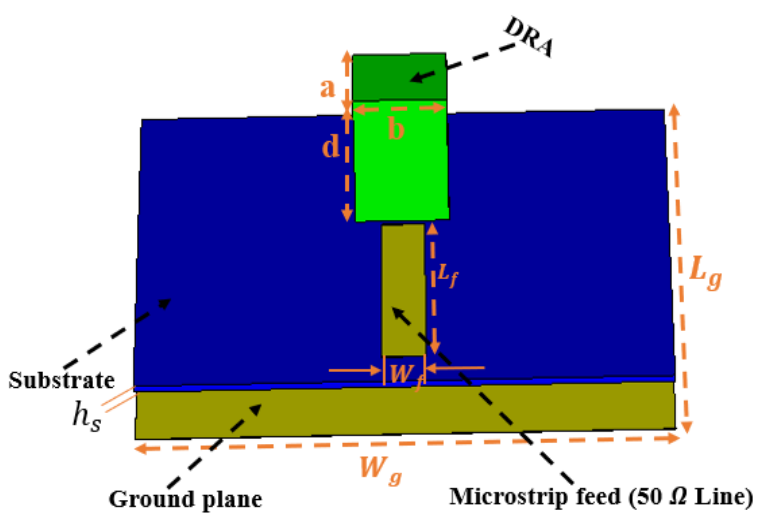

Figure 1. The geometry of the proposed higher-order mode DRA

\section{RESULTS AND DISCUSSION}

The proposed dielectric resonator antenna design is simulated by CST Microwave studio software. Figure 2 shows the $S_{11}$ of the proposed DRA operating on higher order $\left(T E_{\delta 13}\right)$ mode at the resonating frequency of $28 \mathrm{GHz}$. From the figure, the simulated $-10 \mathrm{~dB}$ impedance bandwidth $S_{11}<-10 \mathrm{~dB}$ of the antenna is $4.6 \%(27.3-28.8 \mathrm{GHz}=1.3 \mathrm{GHz})$. The simulated gain and efficiency of an antenna are depicted 
in Figure 3. concerning the figure, the DRA shows a gain of $5 \mathrm{dBi}$ and high radiation efficiency of $89 \%$. Figure 4 shows the simulated voltage standing wave ratio (VSWR) curve as a function of frequency. It is noted that the VSWR is less than 2 for the whole impedance bandwidth. The simulated normalized radiation pattern of the proposed DRA in the E-and H-plane at $28 \mathrm{GHz}$ is shown in Figure 5. The antenna radiates in the broadside direction. Table 2 shows the results of the proposed DR antenna operating on $T E_{\delta 13}$ mode at $28 \mathrm{GHz}$.

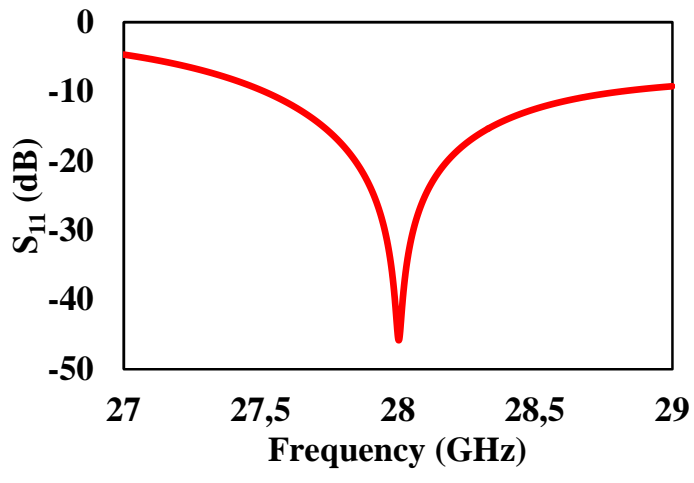

Figure 2. Simulated $S_{11}$ of the proposed DRA

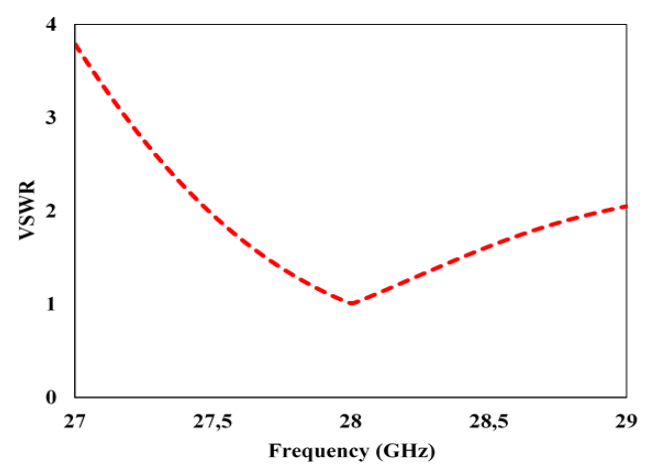

Figure 4. Simulated VSWR versus frequency of the DRA

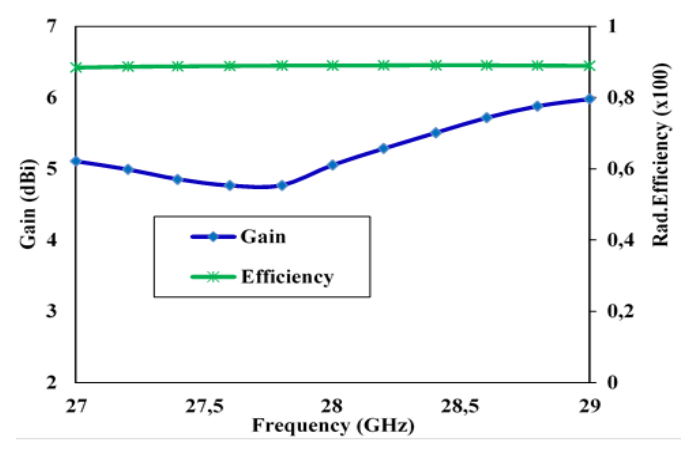

Figure 3. Simulated gain and radiation efficiency versus frequency of the proposed DRA

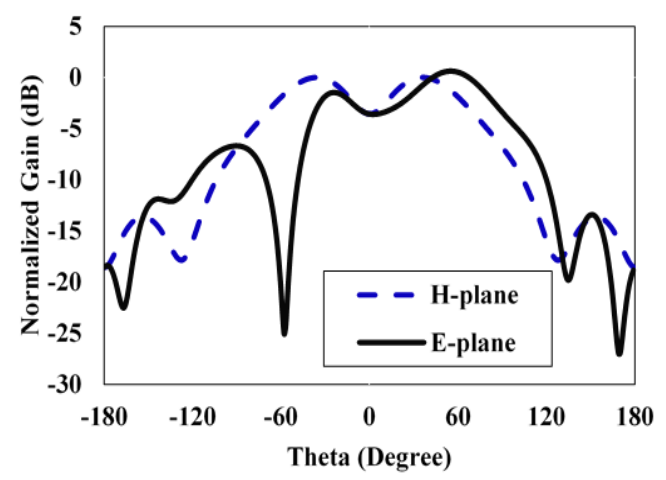

Figure 5. Simulated normalized radiation pattern in the E-plane and $\mathrm{H}$-plane at $28 \mathrm{GHz}$

Table 2. Results of the proposed DRA based on higher order $T E_{\delta 13}$ mode at $28 \mathrm{GHz}$

\begin{tabular}{cccccc}
\hline Mode & $f_{o}(\mathrm{GHz})$ & $\mathrm{BW}(\%)$ & Gain $(\mathrm{dBi})$ & Eff. $(\%)$ & VSWR \\
\hline$T E_{\delta 13}$ & 28 & $4.6 \%$ & 5 & 89 & $<1.2$ \\
\hline$f_{o}$-Resonant frequency in $\mathrm{GHz}$, & $B W$ & -Bandwidth in percentage, Gain - Gain in dBi, Eff. -Efficiency \\
in percentage $(\%), V S W R$ & - Voltage standing wave ratio.
\end{tabular}

\section{CONCLUSION}

Higher order mode dielectric resonator antenna excited using microstrip line is presented and investigated. The proposed antenna achieves an impedance bandwidth of $4.6 \%$, for $\mathrm{VSWR}<2$, covering the frequency range from $27.3 \mathrm{GH}$ to $28.8 \mathrm{GHz}$ with a gain of $5 \mathrm{dBi}$ and high radiation efficiency of $89 \%$. The proposed antenna is small in size and simple structure which can be used for fifth generation $(5 \mathrm{G})$ wireless communication applications. 


\section{ACKNOWLEDGEMENTS}

The authors would like to thank the Universiti Teknologi Malaysia Grant HiCoE 4J415 and UTM Grant (TDR Grant 05G20 and GUP 19H56) for supporting this research work.

\section{REFERENCES}

[1] S. Z. N. Zool Ambia, M. H. Jamaluddin, M.R. Kamarudin, J. Nasir, R.R. Selvaraju, "Evolution of H-Shaped Dielectric Resonator Antenna for 5G Applications," Indonesian Journal of Electrical Engineering and Computer Science, vol. 13, no. 2, pp. 562-568, February 2019.

[2] H. A. Ameen, et al., "A 28 Ghz Four-Channel Phased-Array Transceiver in 65-Nm CMOS Technology for 5G Applications," AEU-International Journal of Electronics and Communications, vol. 98, pp. 19-28, January 2019.

[3] Abinash Gaya, Mohd Haizal Jamaluddin, M. R. Kamarudin, Irfan Ali, “A Wideband Dielectric Resonator Antenna with A Cross Slot Aperture for 5G Communications," TELKOMNIKA Telecommunication Computer Electronics and Control, vol. 17, no. 5, pp. 2218-2225, October 2019.

[4] I. Ali, M. H. Jamaluddin, A. Gaya, and H. A. Rahim, "A Dielectric Resonator Antenna with Enhanced Gain and Bandwidth for 5G Applications,” Sensors, vol. 20, no. 3, pp. 1-12, 2020.

[5] A. Iqbal, A. Smida, O. A. Saraereh, and Q. H. Alsafasfeh, "Cylindrical Dielectric Resonator Antenna-Based Sensors for Liquid Chemical Detection," Sensors, vol. 19, no. 5, pp. 1-9, 2019.

[6] A. A. Id, J. Jung, Y. Yang, K. Lee, S. Yi, and K. C. Hwang, "A 3-D Meandered Probe-Fed Dual-Band Circularly Polarized Dielectric Resonator Antenna," Sensors, vol. 18, no. 8, pp. 1-11, 2018.

[7] G. Varshney, V. S. Pandey and R. S. Yaduvanshi, "Dual-band fan-blade-shaped circularly polarised dielectric resonator antenna," in IET Microwaves, Antennas \& Propagation, vol. 11, no. 13, pp. 1868-1871, 20102017.

[8] J. Liang and S. Zhang, "Orbital Angular Momentum (OAM) Generation by Cylinder Dielectric Resonator Antenna for Future Wireless Communications," in IEEE Access, vol. 4, pp. 9570-9574, 2016.

[9] A. A. Abdulmajid, Y. Khalil and S. Khamas, "Higher-Order-Mode Circularly Polarized Two-Layer Rectangular Dielectric Resonator Antenna," in IEEE Antennas and Wireless Propagation Letters, vol. 17, no. 6, pp. 1114-1117, June 2018.

[10] A. Gupta and R. K. Gangwar, "Dual-Band Circularly Polarized Aperture Coupled Rectangular Dielectric Resonator Antenna for Wireless Applications," in IEEE Access, vol. 6, pp. 11388-11396, 2018.

[11] N. H. Shahadan et al., "Steerable Higher Order Mode Dielectric Resonator Antenna With Parasitic Elements for 5G Applications," in IEEE Access, vol. 5, pp. 22234-22243, 2017.

[12] I. Ali, M. H. Jamaluddin, M. R. Kamarudin, A. Gaya, and R. Selvaraju, "Wideband and High Gain Dielectric Resonator Antenna for 5G Applications," Bulletin of Electrical Engineering and Informatics, vol. 8, no. 3, pp. 1047-1052, September 2019.

[13] T. A. Denidni and Z. Weng, "Rectangular Dielectric Resonator Antenna for Ultrawideband Applications," Electronics Letters, vol. 45, no. 24, pp. 1210-1212, 19 November 2009.

[14] Y. Pan, K. W. Leung and K. Lu, "Compact Quasi-Isotropic Dielectric Resonator Antenna With Small Ground Plane," in IEEE Transactions on Antennas and Propagation, vol. 62, no. 2, pp. 577-585, Feb. 2014.

[15] A. Gaya, M. H. Jamaluddin, M. R. Kamarudin, R. Selvaraju and I. Ali, "Performance Analysis of a Dielectric Resonator Antenna with Different Feeding Technique for 5G Communication," 2018 2nd International Conference on Electrical Engineering and Informatics (ICon EEI), Batam, Indonesia, 2018, pp. 92-97.

[16] R. Chair, A. A. Kishk and K. F. Lee, "Wideband stair-shaped dielectric resonator antennas," in IET Microwaves, Antennas \& Propagation, vol. 1, no. 2, pp. 299-305, April 2007.

[17] I. Ali, M. H. Jamaluddin, M. R. Kamarudin, A. Gaya, and M. H. Dahri, "Gain Enhancement of Dielectric Resonator Antenna for Millimeter Wave Applications," TELKOMNIKA Telecommunication, Computing, Electronics and Control, vol. 17, no. 4, pp. 1670-1673, 2019.

[18] D. Guha and Y. M. M. Antar, "Four-Element Cylindrical Dielectric Resonator Antenna for Wideband MonopoleLike Radiation," in IEEE Transactions on Antennas and Propagation, vol. 54, no. 9, pp. 2657-2662, Sept. 2006.

[19] N. K. Mishra, S. Das, and D. K. Vishwakarma, "Beam Steered Linear Array of Cylindrical Dielectric Resonator Antenna," AEUE - Int. J. Electron. Commun., vol. 98, pp. 106-113, January 2019.

[20] M. W. McAllister, S. A. Long and G. L. Conway, "Rectangular dielectric resonator antenna," in Electronics Letters, vol. 19, no. 6, pp. 218-219, 17 March 1983.

[21] P. Patel, B. Mukherjee and J. Mukherjee, "A novel pierced rectangular dielectric resonator antenna for wideband communication systems," 2014 IEEE International Conference on Electronics, Computing and Communication Technologies (CONECCT), Bangalore, pp. 1-5, 2014.

[22] B. Mukherjee, P. Patel and J. Mukherjee, "A Novel Hemispherical Dielectric Resonator Antenna With Complementary Split-Ring-Shaped Slots and Resonator for Wideband and Low Cross-Polar Applications," in IEEE Antennas and Propagation Magazine, vol. 57, no. 1, pp. 120-128, Feb. 2015.

[23] H. Y. Lo, K. W. Leung, K. M. Luk and E. K. N. Yung, "Low profile equilateral-triangular dielectric resonator antenna of very high permittivity," in Electronics Letters, vol. 35, no. 25, pp. 2164-2166, 9 Dec. 1999.

[24] S. Maity and B. Gupta, "Experimental Investigations on Wideband Triangular Dielectric Resonator Antenna," in IEEE Transactions on Antennas and Propagation, vol. 64, no. 12, pp. 5483-5486, Dec. 2016.

[25] U. Illahi, J. Iqbal, M. I. Sulaiman, M Alam, M. S. Mazliham, M. H. Jamaluddin, "Circularly Polarized Rectangular Dielectric Resonator Antenna Excited by an Off-Set Conformal Metal Strip," Indonesian Journal of Electrical Engineering and Computer Science, vol. 15, no. 2, pp. 902-909, August 2019. 
[26] Y. M. Pan and S. Y. Zheng, "A Low-Profile Stacked Dielectric Resonator Antenna With High-Gain and Wide Bandwidth," in IEEE Antennas and Wireless Propagation Letters, vol. 15, pp. 68-71, 2016.

[27] A. A. Kishk, Xiao Zhang, A. W. Glisson and D. Kajfez, "Numerical analysis of stacked dielectric resonator antennas excited by a coaxial probe for wideband applications," in IEEE Transactions on Antennas and Propagation, vol. 51, no. 8, pp. 1996-2006, Aug. 2003.

[28] M. J. Al-Hasan, T. A. Denidni and A. R. Sebak, "Millimeter-Wave EBG-Based Aperture-Coupled Dielectric Resonator Antenna," in IEEE Transactions on Antennas and Propagation, vol. 61, no. 8, pp. 4354-4357, Aug. 2013.

[29] T. A. Denidni, Y. Coulibaly and H. Boutayeb, "Hybrid Dielectric Resonator Antenna With Circular MushroomLike Structure for Gain Improvement," in IEEE Transactions on Antennas and Propagation, vol. 57, no. 4, pp. 1043-1049, April 2009.

[30] R. Kumar Mongia and A. Ittipiboon, "Theoretical and experimental investigations on rectangular dielectric resonator antennas," in IEEE Transactions on Antennas and Propagation, vol. 45, no. 9, pp. 1348-1356, Sept. 1997.

\section{BIOGRAPHIES OF AUTHORS}

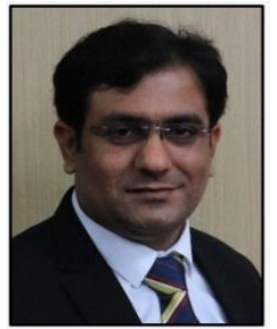

Irfan Ali received the B.E degree in Telecommunications from the Mehran University of Engineering and Technology (MUET), Pakistan, in 2010 and the master's degree in Telecommunications Engineering from NED University of Engineering and Technology in 2014. He is currently pursuing the Ph.D. degree with the Wireless Communication Centre (WCC), Universiti Teknologi Malaysia (UTM). He is a student member in IEEE. His research interests include microstrip patch antennas, dielectric resonator antennas, MIMO antennas, mutual coupling analysis.

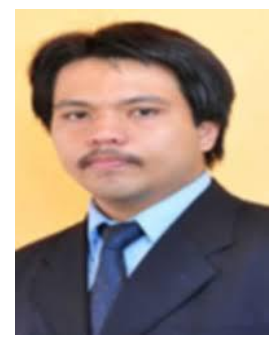

Mohd Haizal Jamaluddin received bachelor's and master's degrees in electrical engineering from Universiti Teknologi Malaysia, Malaysia, in 2003 and 2006, respectively, and the Ph.D. degree in signal processing and telecommunications from the Université de Rennes 1, France, in 2009, with a focus on microwave communication systems and specially antennas such as dielectric resonator and reflectarray and dielectric dome antennas. $\mathrm{He}$ is currently an Associate Professor with the Wireless Communication Centre, School of Electrical Engineering, Universiti Teknologi Malaysia. His research interests include dielectric resonator antennas, printed microstrip antennas, MIMO antennas and DRA reflectarray antennas. He has published more than 100 papers in reputed indexed journals and conference proceedings.

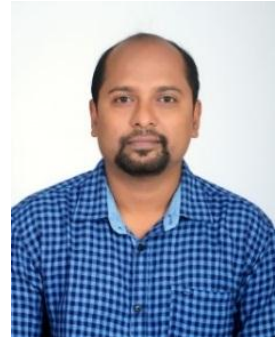

Abinash Gaya is a PhD Student at Wireless Communication Centre (WCC), UTM Johor Bahru. $\mathrm{He}$ has been involved in the Design and Development of Dielectric Resonator Antennas for 5G Communications at WCC. He is also working towards Design of Phased Array Antenna system for $5 \mathrm{G}$ Base Stations. He is a student member in IEEE. 